\title{
Relato de um Processo Investigativo a partir de Proposições Orientadas de Problemas no Ensino de Acústica ${ }^{+}$
}

\author{
Paulo Henrique dos Santos Sartori ${ }^{1}$ \\ Universidade Federal do Pampa \\ Graciela de Lima Freitas ${ }^{1}$ \\ Instituto Estadual de Educação Dinarte Ribeiro \\ Caçapava do Sul - RS
}

\section{Resumo}

O presente estudo trata de uma proposta no âmbito do Ensino de Física, sobre o tema "Estudo do Som". Neste trabalho discute-se o papel das atividades experimentais investigativas em sala de aula relacionadas à Física, por meio do que denominamos Proposições Orientadas de Problemas (POP). Analisa-se como os alunos de um terceiro ano do Ensino Médio Integrado de uma escola pública do município de Caçapava do Sul, RS, se apropriam e interagem com o processo de investigação e quais as relações empíricas são capazes de inferir. Constatou-se que o grupo de alunos realizou as POP de forma autônoma, colaborativa e criteriosa; evidenciando a capacidade de refletir criticamente sobre o processo e denotando um saber-fazer muito próximo ao que se esperaria de uma abordagem típica de investigações científicas, obtendo relações empíricas pertinentes às diversas situações enfrentadas.

Palavras-chave: Atividades Investigativas; Experimentação; Estudo do Som.

\footnotetext{
Abstract

This study deals with a proposal in the field of Physics Education, on the theme "Study of Sound". In this paper we discuss the role of investigative

${ }^{+}$Investigative Process Analysis from Oriented Problems Propositions in Teaching Acoustics

* Recebido: março de 2020. Aceito: maio de 2020.

${ }^{1}$ E-mails: paulosartori@unipampa.edu.br; seduc.gracielafreitas@gmail.com
} 
experimental activities in the classroom related to physics, through what we call Oriented Problems Propositions (OPP). It analyzes how the students of a third year of the Integrated High School of a public school of the city of Caçapava do Sul - RS, appropriate and interact with the investigation process and which empirical relations are able to infer. It was found that the group of students performed the OPP autonomously, collaboratively and carefully; highlighting the ability to reflect critically on the process and denoting a know-how very close to what would be expected from a typical approach of scientific investigations, obtaining empirical relationships relevant to the various situations faced.

Keywords: Investigative Activities; Experimentation; Sound Study.

\section{Introdução}

Na busca de melhorias no Ensino de Física e de o aluno adquirir habilidades que o tornem autônomo na construção do seu conhecimento sobre esta Ciência, discutiremos o papel de atividades experimentais investigativas na prática escolar e, também, apresentaremos uma proposta de ensino que utiliza atividades que instiguem a investigação em sala de aula. Essas atividades foram organizadas em Proposições Orientadas de Problemas (POP), as quais têm como objetivo a obtenção de relações empíricas, isto é, resultados derivados das observações e experimentos realizados pelos alunos. As atividades foram aplicadas em uma turma de alunos de Ensino Médio de uma escola pública de Caçapava do Sul. O tema "Estudo do Som" foi escolhido para ser desenvolvido nessa proposta de ensino, tendo em vista sua íntima ligação, vivencial e contextual, com os adolescentes. Como apontam Steffani et al.,

\footnotetext{
O som é um tema fascinante e envolvente, que pode ser amplamente explorado por professores de ciências, de matemática, de fisica, de música ou de biologia, até porque, é um tema de grande interesse para a maior parte dos alunos. Em toda e qualquer turma de alunos há algum que se interessa por música, toca algum instrumento, ou tem um instrumento musical em casa. Isso para não falar naqueles que conseguem "fazer música" soprando numa folha de árvore ou de papel, ou na boca de garrafas parcialmente preenchidas com água, ou simulando um xilofone com copos de cristal (STEFFANI et al., 2014, p. 2).
}

O Ensino de Física através da discussão de conceitos, leis e fórmulas, tem se apresentado, com certa frequência, de forma desarticulada e distante do cotidiano dos alunos e também dos professores, como está enfatizado nos Parâmetros Curriculares Nacionais (PCN), referente aos conhecimentos desta área (BRASIL, 1999). Segundo Azevedo (2006), as últimas investigações sugerem que ao separar a resolução de problemas, a teoria e as aulas práticas, os alunos acabam possuindo uma ideia alterada do que é Ciência, sendo que tais 
formas de trabalho deveriam estar relacionadas umas com as outras, formando um todo coerente e interdependente.

Nos PCN destaca-se que é preciso rediscutir qual Física ensinar para que haja uma melhor compreensão do mundo e uma formação para a cidadania mais adequada, isto é, não se trata de preparar diferentes listas de conteúdo, mas de promover um conhecimento contextualizado e próximo da vida do aluno. Portanto, para isso, é importante levar em consideração o mundo vivencial dos alunos, sua realidade próxima ou distante, os objetos e fenômenos com que efetivamente lidam ou os problemas e indagações que movem sua curiosidade. Assim, trabalhos de pesquisa em ensino revelam que os educandos aprendem mais sobre Ciência e desenvolvem melhor seus conhecimentos conceituais quando participam de investigações científicas, semelhantes àquelas realizadas no laboratório de pesquisa (HODSON, 1992 apud AZEVEDO, 2006).

O trabalho experimental é uma das ferramentas que o Ensino de Física disponibiliza e que pode ser utilizado para a aprendizagem dos alunos. Assim, de acordo com Delizoicov e Angotti (1994), as experiências despertam o interesse dos alunos e propiciam uma situação de investigação, e se esses dois fatores forem levados em consideração no momento do planejamento das atividades, estas podem constituir situações "ricas no processo de ensinoaprendizagem". Ainda sobre o trabalho experimental, os autores apontam:

Considera-se mais conveniente um trabalho experimental que dê margem à
discussão e interpretação de resultados obtidos (quaisquer que tenham sido), com o
professor atuando no sentido de apresentar e desenvolver conceitos, leis e teorias
envolvidos na experimentação. Desta forma, o professor será um orientador crítico
da aprendizagem, distanciando-se de uma postura autoritária e dogmática no
ensino e possibilitando que os alunos venham a ter uma visão mais adequada do
trabalho em Ciências (DELIZOICOV; ANGOTTI, 1994, p. 22-23).

As atividades experimentais aqui propostas apresentam a característica de utilizar materiais de baixo custo e acessíveis, não necessitando de ambiente de laboratório para serem executadas. Também envolvem o uso de aplicativos para smartphones que simulam instrumentos de laboratório difíceis de serem encontrados nas escolas. Estas particularidades são mencionadas por Borges (2002), para o qual, a realização de atividades práticas equivocadamente implica na necessidade de um espaço com materiais especiais, pois elas podem ser efetivadas em qualquer sala de aula, não necessitando de equipamentos sofisticados. O autor ainda ressalta: "qualquer que seja o método de ensino-aprendizagem escolhido, deve mobilizar a atividade do aprendiz, em lugar de sua passividade" (BORGES, 2002, p. 294). 


\section{Fundamentação teórica}

As propostas que seguem a linha do ensino por investigação com experimentação são consideradas metodologias ou abordagens que auxiliam o Ensino de Física em sala de aula, tornando-o mais contextualizado, dinâmico, atraente e aproximam o educando de como se desenvolve um trabalho científico.

De acordo com Azevedo (2006), a atividade investigativa é uma estratégia importante no Ensino de Física e de Ciências em geral. As atividades investigativas tanto podem ser questões abertas e problemas abertos como demonstrações investigativas e laboratórios abertos. Mas para que uma atividade possa ser considerada investigativa Azevedo sinaliza:

[...] a ação do aluno não deve se limitar apenas ao trabalho de manipulação ou observação, ela deve também conter características de um trabalho científico: o aluno deve refletir, discutir, explicar, relatar, o que dará ao seu trabalho as características de uma investigação científica. Essa investigação, porém, deve ser fundamentada, ou seja, é importante que uma atividade de investigação faça sentido para o aluno, de modo que ele saiba o porquê de estar investigando o fenômeno que a ele é apresentado (AZEVEDO, 2006, p. 21).

Ao desenvolvermos atividades dessa natureza, a qual pode ser considerada investigativa conforme seu planejamento, objetivo e desenvolvimento, não devemos esquecer que na construção de um conhecimento, o processo é tão importante quanto o produto. $\mathrm{O}$ aluno, através desse tipo de atividade, pode dar início à formação de sua autonomia, pois a partir do processo de pensar, o qual é resultado da participação do aluno no seu método de aprendizagem, sai de uma postura passiva e inicia a ação sobre o seu objeto de estudo, relacionando esse objeto com acontecimentos e procurando as causas dessa relação, para assim ter uma explicação para suas ações/interações (CARVALHO et al., 1998 apud AZEVEDO, 2006).

A observação e a ação são pressupostos básicos para uma atividade investigativa. Por meio desses, os alunos poderão perceber que o conhecimento científico ocorre através de uma construção, verificando seu caráter dinâmico e aberto, contrariando o que descrevem os livros de Ciências sobre o método científico, o qual é caracterizado como algo fechado e que segue uma sequência lógica e rígida (AZEVEDO, 2006).

Por meio da abordagem com atividades investigativas, Azevedo aponta alguns escopos pedagógicos que podem ser atingidos:

Habilidades - de manipular, questionar, investigar, organizar, comunicar; Conceitos - por exemplo: hipótese, modelo teórico, categoria taxionômica;

Habilidades cognitivas - pensamento crítico, solução de problemas, aplicação, sintese; 
Compreensão da natureza da ciência - empreendimento científico, cientistas e como eles trabalham, a existência de uma multiplicidade de métodos cientificos, interrelações entre ciência e tecnologia e entre várias disciplinas científicas;

Atitudes - por exemplo: curiosidade, interesse, correr risco, objetividade, precisão, perseverança, satisfação, responsabilidade, consenso, colaboração, gostar de ciência (AZEVEDO, 2006, p. 24).

Seguindo esta linha, pode-se dar início à discussão da atividade experimental investigativa que tem como característica o desenvolvimento científico das atividades em sala de aula. Assim:

[...] numa estratégia investigativa muitas competências cientificas - identificação de variáveis, construção de tabelas e gráficos, descrição de relações entre variáveis, seleção e tratamento de informação, formulação de hipóteses, planejamento e execução de investigações, por exemplo, podem ser sucessivamente utilizadas e aperfeiçoadas promovendo o desenvolvimento do raciocínio, do pensamento crítico, da auto-aprendizagem e da capacidade de resolver problemas (REIS, 1996, apud FERNANDES; SILVA, 2004, p. 47).

Desta forma, professores e alunos poderão envolver-se em conjunto numa atividade que pode ser ao mesmo tempo "construtivista, reflexiva e interativa" (HODSON, 1994 apud FERNANDES; SILVA, 2004, p. 47).

Azevedo (2006) descreve categorias de atividades investigativas que poderão ser tratadas como problemas a serem resolvidos: demonstrações investigativas, laboratório aberto, questões abertas e problemas abertos. Neste estudo, a proposta sugerida aos alunos se aproxima das características das atividades investigativas do tipo laboratório aberto, pois trata-se de atividades experimentais de caráter investigativo para a resolução de problemas. Uma atividade de laboratório aberto busca a solução de uma questão (problema), que será respondida por uma experiência. Esse trajeto até a resposta é basicamente dividido em seis momentos: proposta do problema, levantamento de hipóteses, elaboração do plano de trabalho, montagem do arranjo experimental e coleta de dados, análise dos dados e conclusão (AZEVEDO, 2006, p. 27-29).

Parente (2012) fez uma prospecção a respeito das várias modalidades de ensino investigativo e constatou que ele pode ser utilizado em diversas situações: o ensino por descobrimento dirigido, a investigação dirigida, a investigação orientada, o ensino por pesquisa, o educar pela pesquisa e a investigação escolar. Para a autora, as principais características desse processo de ensino por investigação são:

[...] a seleção e a formulação de um problema; a formulação e a seleção de conjecturas ou hipóteses iniciais; o planejamento necessário para dar solução ao problema investigado; a execução do planejamento acordado; a preparação e análise dos dados obtidos; a expressão dos resultados; a conclusão do trabalho e, 
por fim, a comunicação para a formulação dos resultados da investigação (PARENTE, 2012, p. 45).

Nesse sentido, as POP, de modo geral, apresentam aspectos similares as de uma investigação dirigida, orientada e escolar. São uma forma de investigação baseada nos principais pressupostos do ensino investigativo aqui delineados. A 'Proposição' se refere ao estabelecimento de uma proposta de trabalho, uma "caminhada a ser trilhada", elaborada pelo organizador e promotor da ação: o pesquisador e/ou professor. É 'Orientada' no sentido de guiar, quando necessário, o alinhamento de questões ou aspectos que visem o melhor rumo do trabalho investigativo, desde seu planejamento até sua execução. E, por fim, envolve um 'Problema', uma questão de partida para ser resolvida, que funciona como "força motriz" para o engajamento dos alunos.

Para a realização das atividades os alunos utilizaram como suporte instrumental um recurso tecnológico bastante difundido entre os estudantes nos dias de hoje: o smartphone. A motivação para o uso desta ferramenta, além da familiaridade, também foi devido à indisponibilidade de equipamentos específicos (de laboratório) para a medição das grandezas físicas envolvidas nas atividades. Assim, os alunos fizeram downloads dos aplicativos que auxiliaram nas atividades experimentais como o decibelímetro, o frequencímetro e o gerador de áudio. As tecnologias da informação e comunicação (TIC) estão presentes em nosso dia a dia e na vida dos estudantes. Partindo disto, as atividades experimentais podem se valer das TIC como ferramentas em seu favor, mesmo diante de suas limitações técnicas quando comparados aos aparelhos profissionais.

Embora com propósitos distintos ao que foi realizado neste trabalho, diversos autores têm referendado a inserção dos smartphones e seus aplicativos no ensino de Ciências. Para Barbosa et al. (2017) as simulações mediadas pelo smartphone podem servir como um complemento no processo de ensino e de aprendizagem, mas não devem substituir as aulas em laboratório, configurando-se como um recurso a mais no ensino. Ainda, de acordo com os autores, o uso pedagógico do smartphone em sala de aula, contribui para o Ensino de Física, propiciando "aulas lúdicas onde os alunos têm um papel ativo no processo de ensino e aprendizagem, enquanto o professor tem a função de facilitador, orientador e provocador de reflexões" (BARBOSA et al., 2017, p. 2). Consideram, ainda, que, no ambiente educacional "[...] a multimídia interativa é um instrumento bem ajustado a uma pedagogia ativa, pois favorece uma atitude exploratória, até mesmo lúdica, diante do assunto a ser assimilado" (LÉVY, 1993, apud BARBOSA et al., 2017, p. 3).

Guedes (2015) resolveu "pesquisar aplicativos voltados para a geração de sinais em celulares e verificar a viabilidade de utilizá-los como um gerador de sinais em um experimento de baixo custo para estudo das ondas estacionárias em uma corda" (GUEDES, 2015 , p. 1), justificando, assim, o uso de um telefone com um aplicativo instalado capaz de simular o funcionamento de aparelhos sofisticados e caros para aquisição pelas escolas. Atualmente, em muitos laboratórios de Física de escolas de Ensino Médio, os problemas estão 
desde espaços inadequados para a realização de atividades até a inexistência de equipamentos para a realização de experimentos, tendo como uma possível solução, para contornar esses problemas, a elaboração de experimentos de baixo custo. Portanto, a utilização de telefones (tipo smartphones) por serem comuns e já fazerem parte do dia a dia dos professores e alunos, pode ser uma alternativa viável para substituir, com razoável confiabilidade, instrumentos de laboratório (GUEDES, 2015). O autor destaca a respeito destes modernos aparelhos: "Os smartphones atuais podem ser considerados verdadeiros computadores de bolso, uma vez que, alguns têm poder de processamento e memória similares a computadores do tipo desktop. Outra característica dos smartphones é a grande quantidade de aplicativos voltados para as mais variadas necessidades" (GUEDES, 2015, p. 1).

\section{Desenvolvimento}

As atividades propostas foram integradas e organizadas sob a forma de uma oficina realizada com alunos do terceiro ano do Ensino Médio Integrado do Instituto Estadual de Educação Dinarte Ribeiro do município de Caçapava do Sul. A turma era composta por doze alunos, sendo seis meninas e seis meninos. Para preservar a identidade dos alunos eles foram identificados pela letra 'A' seguida dos números de 1 até 12 . Em relação ao perfil coletivo, a turma apresentou características peculiares como iniciativa, determinação e cooperação. Os alunos, em sua maioria, demonstraram proatividade e, alguns desses alunos, se destacaram por terem uma boa base de conhecimentos que vão "além da sala de aula".

A oficina foi realizada em três módulos (Quadro 1), com duração de dois períodos de aula de quarenta minutos cada, durante as aulas regulares semanais da disciplina de Física.

Quadro 1 - Módulos da oficina.

\begin{tabular}{|c|c|c|}
\hline Módulo & Descrição & Atividades \\
\hline Módulo I & $\begin{array}{l}\text { Desenvolvimento teórico sobre o } \\
\text { som: conceito, caraterísticas, } \\
\text { propriedades, fenômenos e } \\
\text { qualidades fisiológicas. }\end{array}$ & $\begin{array}{l}\text { - Aula expositiva com uso de apresentação } \\
\text { de slides e de um simulador virtual. } \\
\text { - Demonstrações práticas usando os } \\
\text { aplicativos: frequencímetro e gerador de } \\
\text { áudio, e um diapasão. }\end{array}$ \\
\hline Módulo II & $\begin{array}{l}\text { Investigação sobre intensidade do } \\
\text { som }\left(1^{\text {a }} \text { POP }\right) \text {. }\end{array}$ & $\begin{array}{l}\text { Experimento com o uso de materiais } \\
\text { simples e do aplicativo decibelímetro. }\end{array}$ \\
\hline Módulo III & $\begin{array}{l}\text { - Investigação sobre a frequência da } \\
\left.\text { voz humana ( } 2^{\mathrm{a}} \mathrm{POP}\right) \text {. } \\
\text { - Verificação da ressonância e do } \\
\text { timbre. }\end{array}$ & $\begin{array}{l}\text { - Experimento com o uso do aplicativo } \\
\text { frequencímetro. } \\
\text { - Demonstrações práticas realizadas com } \\
\text { materiais simples e o aplicativo gerador de } \\
\text { áudio. }\end{array}$ \\
\hline
\end{tabular}


Para a coleta de dados, utilizamos: folhas de registros contendo as anotações dos alunos; observações próprias dos pesquisadores relatadas em textos descritivos e gravações de áudio transcritas.

No primeiro módulo foi desenvolvida a teoria básica para dar suporte às atividades práticas em sequência, a qual foi chamada de apresentação conceitual. Foram apresentados os conteúdos, iniciando com uma problematização sobre questões sociais relacionados ao som, seguindo, então, com a problematização sobre "O que é o som?" e apresentando os conteúdos formais relacionados ao tema: ondas sonoras, velocidade de propagação do som, intervalo de frequências audíveis, sensação sonora, qualidades fisiológicas do som (altura, intensidade e timbre), eco e reverberação. Estes assuntos foram desenvolvidos no formato de apresentação de slides, fundamentados no livro 'Ser Protagonista: Física' de autoria de Angelo Stefanovits. Na sequência, foram feitas demonstrações com o simulador virtual 'Som' no sítio da Internet PhET Interactive Simulations (https://phet.colorado.edu/pt_BR/simulation/legacy/sound) (Fig. 1 e 2). De forma auxiliar, para demonstração de algumas propriedades sonoras, utilizouse o diapasão de $440 \mathrm{~Hz}$, e os aplicativos frequencímetro (verificando a frequência do diapasão e gerador de áudio (produzindo ondas sonoras de diferentes alturas). No encerramento desse módulo foi indicada a lista de aplicativos (Anexo 1) que os alunos deveriam instalar nos seus smartphones para serem utilizados nas próximas etapas.

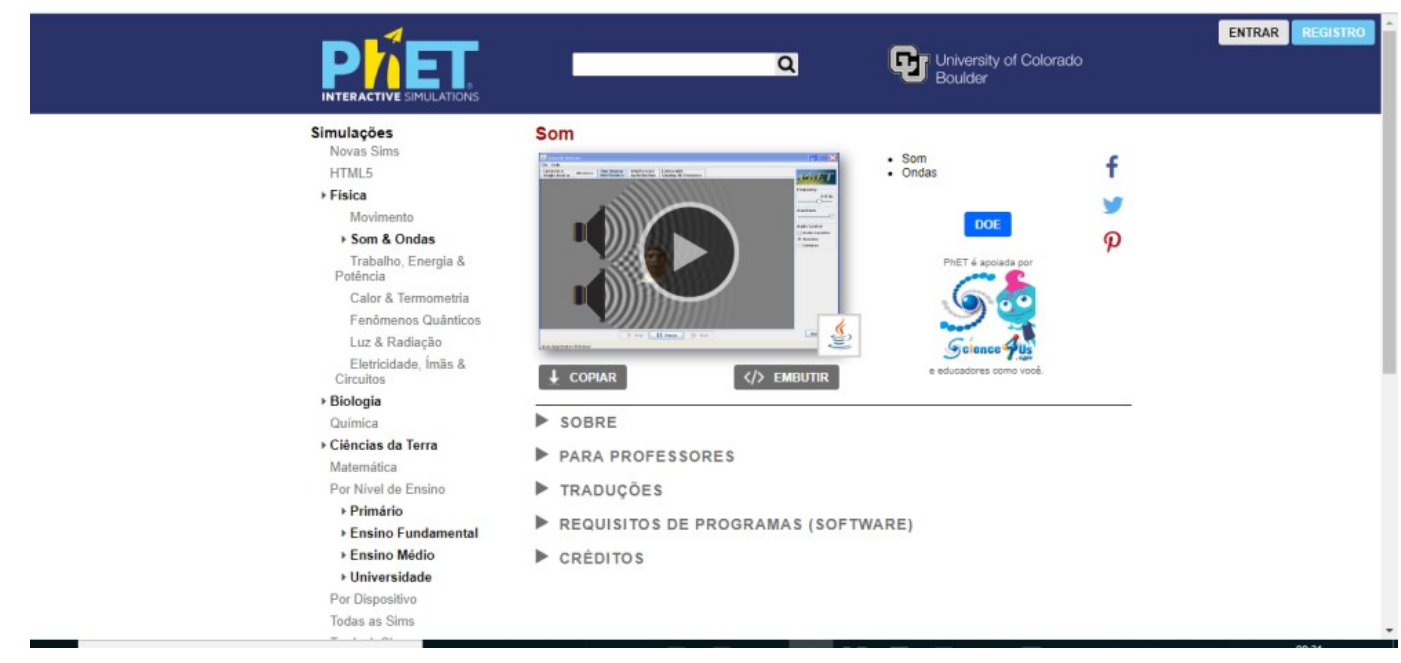

Fig. 1 - Sítio da Internet PhET Interactive Simulations.

Nos módulos seguintes, foram realizadas as atividades práticas com o propósito de resolução das POP, as quais foram precedidas pela explicação do funcionamento dos aplicativos.

No módulo II foram disponibilizados os seguintes materiais (Fig. 3):

- Bumbo;

- Martelo de madeira;

- Decibelímetro (aplicativo); 
- $\quad$ Trena (30 m).



Fig. 2 -Simulador virtual: som. PhET Interactive Simulations.

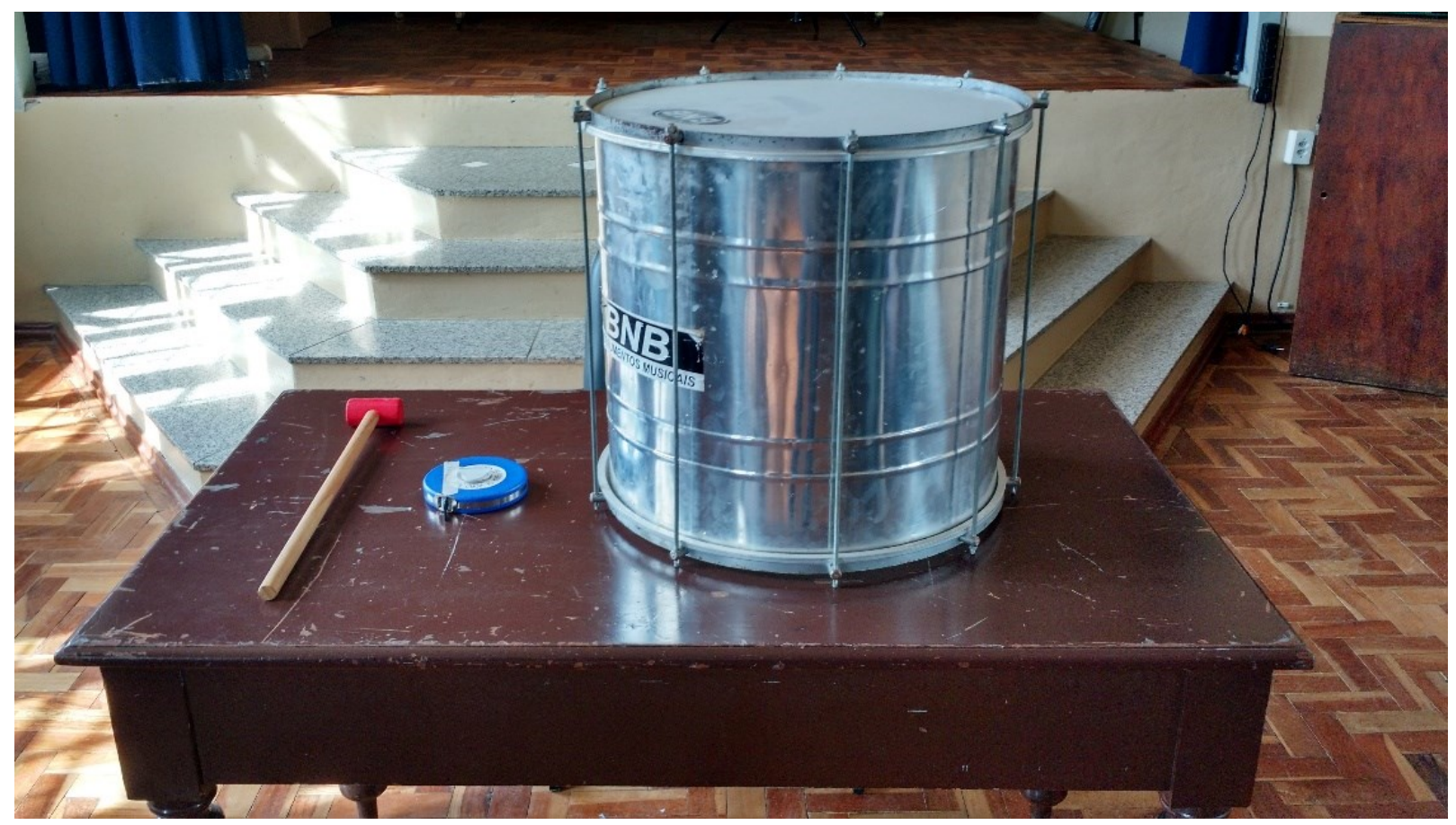

Fig. 3 -Materiais utilizados no módulo 2. 
Os alunos receberam material (Fig. 4) para anotações do passo a passo da atividade, em que deveriam responder à proposição e anotar os resultados obtidos, utilizando também o aplicativo decibelímetro.

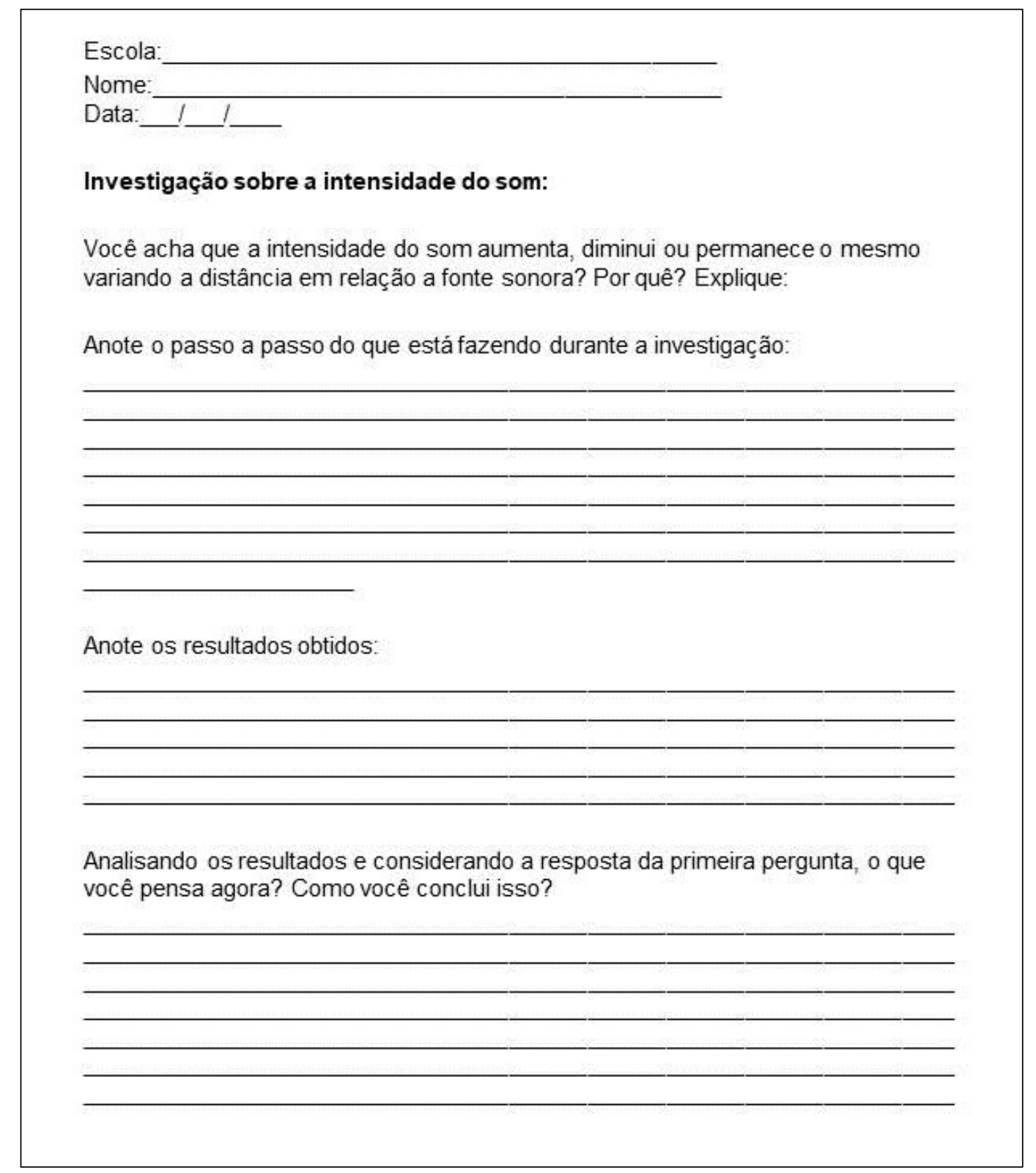

Fig. 4 - Folha de registros da primeira Proposição Orientada de Problema.

No módulo III, os alunos deveriam investigar a própria voz, utilizando o aplicativo frequencímetro, acompanhando a atividade por meio das orientações e fazendo seus registros no material fornecido (Fig. 5).

Neste módulo, para concluir o estudo sobre o som, também foram realizadas duas demonstrações experimentais, sem a finalidade de produzir elementos para análise. Elas serão 
apresentadas nos resultados para não prejudicar a perspectiva da sequência e lógica dos eventos.

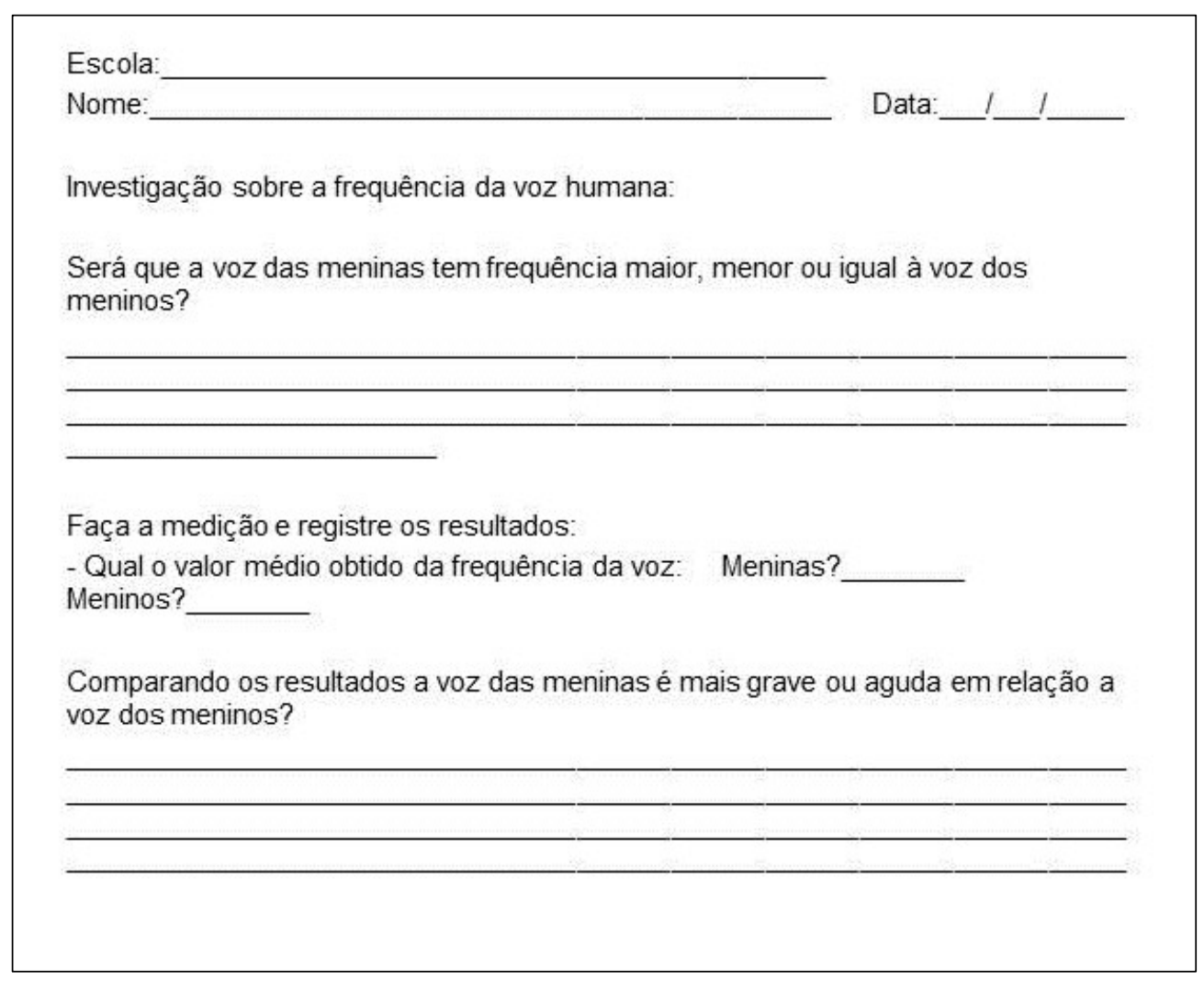

Fig. 5 - Folha de registros da segunda Proposição Orientada de Problema.

\section{Discussão e Análise dos resultados}

\section{Módulo I - Apresentação Conceitual}

Este módulo foi precedido por uma problematização inicial, que serviu para dar início ao estudo do tema sobre o som. Os alunos ao serem perguntados sobre "Quais os problemas que você consegue identificar em nossa cidade?", citaram exemplos como "a falta de educação no trânsito", "os buracos nas ruas", "a falta de trabalho", "o barulho", "cachorros nas ruas" e outros. Entre os problemas citados, pode-se notar que os alunos citaram "o barulho" como um problema na cidade que está relacionado ao tema que será estudado. A respeito do assunto "barulho", foi solicitado que dessem exemplos e eles citaram os carros (particulares) com som e o som "alto" nas casas. Em seguida foi apresentada a próxima pergunta para "afunilar" as respostas: "Dentre esses problemas, algum está relacionado ao desrespeito entre as pessoas?". Eles responderam "a educação no trânsito" e "o barulho", fazendo menção a um problema ocorrido na cidade (Caçapava do Sul) em decorrência de um problema relacionado ao "som alto". Questionados sobre o que incialmente ocasionou toda a 
situação presenciada pela comunidade e também exposta a nível nacional, os alunos prontamente responderam que "os vizinhos não respeitaram os outros vizinhos" e que existe uma lei para ser seguida. Prosseguindo com as perguntas, foi indagado se "Podemos usar a Física para tratar do assunto?", ao que responderam instantaneamente que "sim, usando a acústica". E, finalmente, ao responderem sobre "Como poderíamos resolvê-lo (o problema)?", disseram que seria "conversando e fazendo campanhas de conscientização". Nesta primeira parte da oficina estavam presentes oito alunos.

\section{Módulo II - Investigação sobre a intensidade do som}

Nesta atividade, após o lançamento da pergunta (problema), houve primeiramente uma discussão entre os alunos, em seguida partiram para as medidas. Toda a montagem experimental e a condução sobre a forma de como abordar o problema ficou sob a responsabilidade do grupo. Eles usaram dois smartphones com o aplicativo decibelímetro previamente instalado. Notou-se que souberam acionar os recursos do aplicativo fazendo uso adequado do aparelho, com muita facilidade. Produziram som batendo o martelo no bumbo. Questionavam entre eles se as "batidas" eram com a mesma intensidade. As medições eram feitas com certo padrão idealizado pelos próprios alunos. Os dados eram obtidos verificando a batida com um dos smartphones e com a trena suspensa (Fig. 6). Assim, realizaram as anotações. Houve, então, uma intervenção, na qual se sugeriu estender a trena no chão e distribuir os smartphones para a obtenção dos dados ao longo da trena. Essa orientação foi dada para direcionar o trabalho de investigação no sentido de torná-lo mais produtivo e para gerar resultados de uma forma mais apropriada.

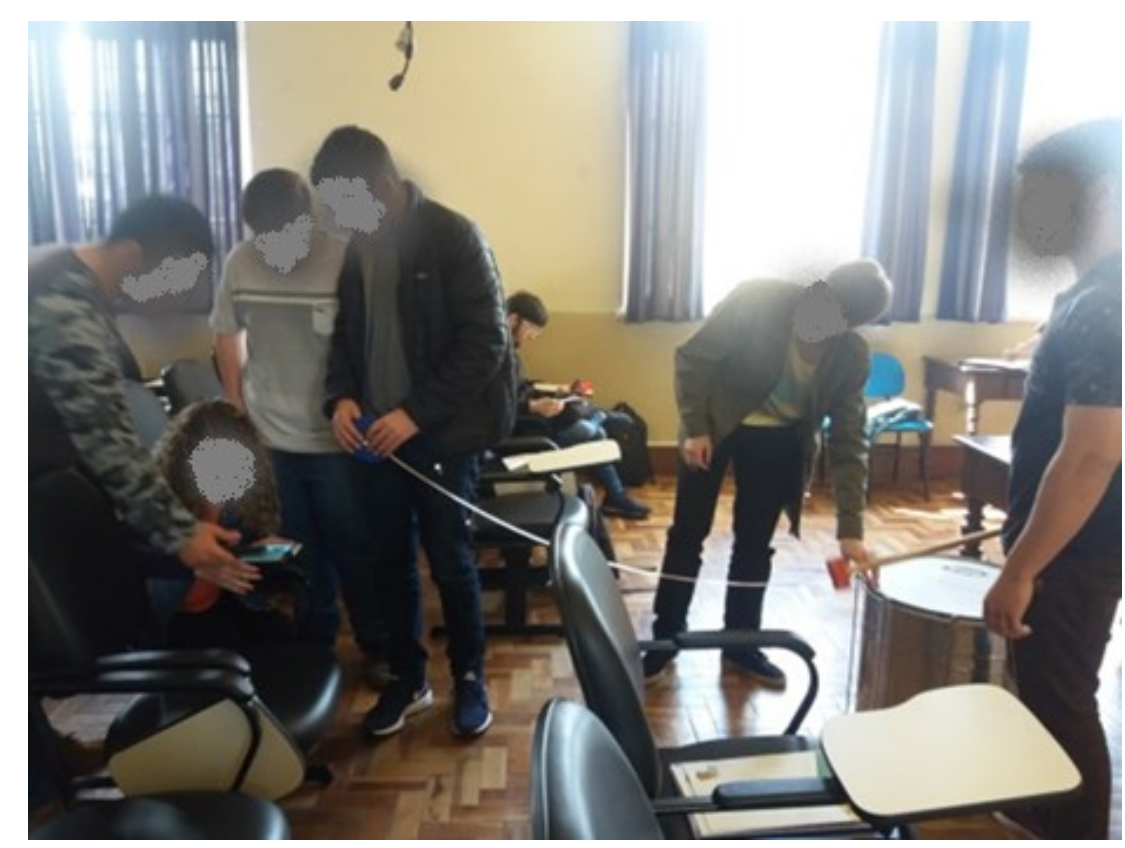

Fig. 6-Os alunos, na segunda fase da oficina, realizando as medições. 
Os alunos discutiram e anotaram as medidas com o auxílio do aplicativo decibelímetro e notaram que havia certo padrão (valores constantes). Comentaram, também, que a última marcação poderia ser o "retorno do som", por isso a medida diferente. Durante o desenvolvimento da atividade constataram algumas diferenças nos valores obtidos dos aparelhos, sendo que um dos alunos afirmou: "Estão descalibrados", ao que outro aluno complementou: "Acho que tem uns microfones melhores que outros". Então, pegaram outros smartphones para ajudar na medição, totalizando 5 (cinco) aparelhos, porque acreditavam que os aplicativos deveriam ser iguais (da mesma marca). Fizeram várias medições comparando os dados obtidos. Houve a presença de nove alunos, mas apenas cinco apresentaram suas respostas no material entregue a eles.

Destaca-se, inicialmente, que os alunos utilizaram os recursos do aplicativo de modo imediato e com bastante desenvoltura. Tais habilidades percebidas são apontadas por Silva (2013) quando afirma: "O envolvimento dos estudantes, quando em contato com aplicativos, é de modo intuitivo, com apenas algumas instruções, sem a utilização de roteiros específicos".

Os alunos demonstraram a necessidade de controlar variáveis e apontaram alternativas para controlá-las, como no caso da batida no tambor. Ao detectarem que, em cada medição a força da batida não era a mesma, discutiram uma forma de produzir batidas com a mesma intensidade: "bate com a mesma força". Constatando que isso não seria possível, pensaram em deixar cair o martelo de uma mesma altura sobre o tambor - solução que é adequada para resolver o problema, criativa e sem a necessidade de incorporar à investigação qualquer outro instrumento ou recurso material adicional.

De forma adequada, os estudantes souberam tomar as medidas de distância, através da trena, e do nível de intensidade sonora, através do decibelímetro, e repetiram as medições para certificarem-se dos resultados. Organizaram as "tarefas" de tal modo que cada aluno se colocou numa função que julgava mais capacitado para executá-la (controlar as batidas, fazer as anotações, medir as distâncias, medir o nível de intensidade sonora, etc.). Isso denota uma auto-organização sem qualquer orientação ou determinação prévia, minimizando a interferência do professor no processo, atuando somente quando julgar necessário. Assim, aparecem, segundo Junior e Coelho (2013)

\section{[...] a aprendizagem procedimental que envolve o conhecimento $e$ o desenvolvimento de habilidades da prática (medir, calcular, construir dispositivos, questionar) e a aprendizagem atitudinal que envolve o desenvolvimento de posturas em relação ao conhecimento científico e a sala de aula (motivação para o estudo da ciência, a comunicação científica, o diálogo, o respeito à fala do colega) (AZEVEDO, 2004; CARVALHO, 2009 apud JUNIOR e COELHO, 2013, p. 8).}

Os conhecimentos científicos previamente estudados no módulo I foram apropriadamente entendidos, como no caso da "reflexão do som" no fundo da parede para explicar uma possível distorção nos valores obtidos, referindo-se a esta situação como "retorno do som". 
De acordo com as anotações que fizeram em seus materiais, os alunos responderam:

1) Você acha que a intensidade do som aumenta, diminui ou permanece a mesma à medida que você se afasta da fonte sonora? Por quê? Explique.

A1: "A intensidade diminui, pois as ondas sonoras perdem força conforme se afastam da fonte".

A4: "Diminui em relação ao ouvinte, porém em relação ao emissor continua o mesmo, devido às ondas sonoras não percorrerem um caminho infinito, logo diminuindo conforme a distância entre ouvinte e emissor".

A7: "Diminui, pois, à medida que o ouvinte se afasta da fonte sonora, a intensidade do som vai diminuindo, quanto mais longe estamos de um rádio, por exemplo, menos escutamos o som que ele produz”.

A8: "Diminui, pois conforme o receptor se afasta, as ondas sonoras perdem intensidade, por exemplo: se estamos em um ambiente aberto a $200 \mathrm{~m}$ de distância, a intensidade do som que receberemos estará reduzida em relação a alguém que esteja a 50 $m "$.

A9: "Diminui, pois à medida que você vai se afastando da fonte sonora o som vai se diminuindo. Um exemplo, quando você passa numa loja e o som está ligado o volume é alto, mas quando você se afasta o som começa a diminuir e os outros sons a volta ficam mais claros".

2) Analisando os resultados e considerando sua resposta da primeira pergunta, o que você pensa agora? Como você concluiu isso?

A1: "A intensidade se mantém, já que não houve variação muito acentuada entre os dados obtidos".

A4: "Que aparentemente não há mudança pelo menos não em metros, ou 9 metros, em um ambiente fechado, com influência de corpos, mas a resposta em si é não houve mudança”.

A7: “Analisa-se que a intensidade mantém, já que não aconteceu variação muito acentuada/exata entre as obtidas a cada distância".

A8: "O teste foi realizado em um ambiente fechado, assim, a reverberação deve ter influenciado os resultados em diferentes distâncias entre 1 e $9 \mathrm{~m}$ foram similares. Então, em ambientes fechados a intensidade não parece mudar, já para ambientes abertos são necessários testes”.

A9: "Varia conforme a distância, espaço e a direção de onde o som foi iniciado e também a força de como foi projetado o som pode vim a mudar. E o decibelímetro também varia o resultado conforme o microfone de cada celular utilizado, pois cada um atinge uma frequência sonora diferente”.

Percebe-se claramente que todos manifestaram um pensamento inicial que é condizente com o que é previsto teoricamente e reforçado pelo senso comum. No entanto ao realizarem as investigações propostas e após analisarem os dados obtidos, constataram que o 
comportamento da intensidade sonora que era esperado não correspondia com a realidade. Tal percepção levou-os a repetir os procedimentos com mais cuidado e rigor, não no sentido de obter um valor médio para os resultados, mas sim porque os dados não concordavam com suas expectativas. Após a confirmação dos dados e, apesar de contrariados com os mesmos, fizeram suas conclusões baseados na credibilidade científica das informações geradas pelos instrumentos de medida utilizados. Essa atitude é totalmente compatível com a atitude crítica que se espera na condução de uma investigação científica, conforme aponta Reis (1996, apud FERNANDES; SILVA, 2004) a "seleção e tratamento de informação, formulação de hipóteses, planejamento e execução de investigações, por exemplo, podem ser sucessivamente utilizadas e aperfeiçoadas promovendo o desenvolvimento do raciocínio, do pensamento crítico".

Além disso, vários alunos contextualizaram suas conclusões apontando fatores que poderiam ter influenciado nos resultados e referindo-se a condições do ambiente. Os alunos A4 e A8 destacam o "ambiente fechado", indicando apropriadamente as circunstâncias em que aqueles resultados são válidos, preocupando-se inclusive de salientar a distância total medida ("9 m") como um limitador do que pode ser apurado. O aluno A8 aponta, de modo cauteloso, que para ambientes abertos não se pode garantir a priori o que vai acontecer pois "são necessários testes" o que claramente denota a incorporação de um método de investigação científica. $\mathrm{O}$ aluno A9 pondera a respeito das diferenças de resultados estarem associadas ao "microfone de cada celular utilizado" o que corresponde plenamente com os alertas do fabricante do aplicativo (ver Anexo 2): os valores obtidos dependem tanto do sistema operacional quanto do modelo e da marca dos aparelhos. Essa falta de uniformidade foi percebida e apontada.

Os alunos A8 e A9 indicam aspectos físicos como variáveis intervenientes no problema (que não tiveram controle), como possíveis influenciadores nos dados, tais como "reverberação", "direção de onde o som foi iniciado" e "a força de como foi projetado o som". Tais argumentos evidenciam a preocupação em fundamentar, baseados no conhecimento de Física, aquilo que poderia justificar os resultados encontrados.

\section{Módulo III - Investigação sobre a frequência da voz humana}

Nesse último módulo, precedido da explicação do funcionamento dos aplicativos frequencímetro e gerador de áudio, fez-se, também, uma demonstração didática do uso destes aplicativos para auxiliar na compreensão de alguns fenômenos acústicos.

Utilizando o frequencímetro e a voz, os alunos deveriam responder as perguntas e desenvolver os seguintes passos:

1) Será que a voz das meninas tem frequência maior, menor ou igual a voz dos meninos? Fazer a medição e registrar os resultados. 
Os alunos, com boa disposição, prontamente tomaram a iniciativa de fazer os testes das vozes. Escolheram por alguém, entre eles, para fazer as anotações e todos participaram utilizando a própria voz para ser analisada. As respostas ao primeiro questionamento foram:

A1: "Maior, por ser geralmente mais aguda".

A2: “A voz das meninas tem frequência maior por possuir uma maior tendência em ser aguda".

A3: “A voz das meninas apresenta ser mais aguda”.

A4: "Meninos".

A5: "A voz das meninas tem frequência maior por termos o som mais agudo".

A6: "Acredito que maior, por ser em maioria uma voz mais aguda do que a dos meninos".

A7: "Sabemos que na maioria dos casos a voz dos homens é bem mais grave que a das mulheres, que é mais aguda, então acredito que tenha frequência menor que a das meninas".

A8: "Tem frequência maior".

Antes de realizarem as medições, os alunos discutiram sobre a escolha de uma frase ou palavra que deveria ser dita por todos para servir como padrão. Escolheram, após acatarem o argumento de que falar uma letra seria mais fácil, a letra "a". Depois, debateram sobre quanto tempo a letra deveria ser dita, estabelecendo o tempo de 5 (cinco) segundos. Essas considerações prévias denotam uma preocupação com o estabelecimento de padrões necessários para que a produção dos dados fosse uniforme e obtida a partir de condições inicias iguais ou as mais próximas possíveis.

Ao realizarem as primeiras medidas, perceberam que "a tonalidade" da voz estava variando, atingindo valores máximo e mínimo, durante o tempo da fala. Um dos alunos questionou: “Qual valor pegar? O maior ou o mínimo?”. Para sanar este problema, resolveram anotar o valor máximo e o valor mínimo atingidos, sendo bastante cuidadosos com os registros e, depois, calcular o valor médio da frequência da voz de cada um. Nesse momento houve certo impasse sobre como deveria ser calculado esse valor, mas a decisão final foi acertada.

Outro procedimento adotado, que foi importante para a tomada dos dados, foi o cuidado em fazer silêncio enquanto a medida estava sendo feita, pois eles já haviam percebido que outras fontes sonoras poderiam interferir na captação do som. Asseguraram-se, inclusive, de manterem a mesma distância do microfone do smartphone em relação à boca de quem produzia o som.

Todas estas atitudes revelam o discernimento a respeito da necessidade de controle de possíveis variáveis.

2) Qual o valor médio da frequência da voz das meninas? E dos meninos?

Resultados obtidos pelo grupo:

- Meninas: 1.410,6 Hz. 
- Meninos: 1.215,9 Hz.

Todos participaram e concluíram, através das anotações, que a frequência da voz das meninas é maior. Isto foi verificado através dos dados obtidos utilizando o aplicativo frequencímetro e dos cálculos realizados (valor médio das frequências).

3) Comparando os resultados, a voz das meninas é mais grave ou mais aguda em relação à voz dos meninos?

Os alunos anotaram em seus materiais as seguintes conclusões:

A1: "Mais aguda".

A2: "A voz das meninas é mais aguda".

A3: "A voz das meninas representa ser mais aguda que a dos meninos".

A4: "Antes da experiência acreditava que a voz masculina tinha uma frequência maior. A voz das garotas é mais aguda que a dos meninos".

A5: "Mais aguda pois é mais alta".

A6: "A voz das meninas, conforme eu acreditava, é mais aguda do que a dos meninos".

A7: "A voz das meninas é mais aguda, pois a média das frequências em $\mathrm{Hz} n a$ medição e comparação entre os meninos e meninas é maior para elas”.

A8: "A voz das meninas é mais aguda".

Para responder corretamente a essa última questão, os alunos teriam que saber relacionar a ideia de som agudo ao som de maior frequência e a ideia de som grave ao som de menor frequência. Isso estava implícito na questão. Estes conceitos foram aplicados de forma adequada nas respostas de todos os alunos.

Devido a alguns alunos não estarem presentes no módulo I da oficina, alguns conhecimentos se fizeram necessários para estes alunos, conforme verificado em uma das respostas do aluno A5: "Mais aguda, pois é mais alta". O termo usado "alta" demonstra que faltou para esse aluno o conhecimento da linguagem científica; ele tenta responder de forma correta, mas usa um termo não adequado, com popularmente ocorre no dia a dia.

Um fato curioso, que cabe relatar, ocorreu quando a frequência da voz de uma das meninas atingiu um valor muito elevado, gerando descrença por parte dos meninos que ficaram desconfiados em relação aos valores. Eles, então, repetiram quatro vezes a medida para a voz dela. Esse episódio pode ser interpretado como um caso que é considerado 'fora da curva' na linguagem científica. Ou seja, apesar da 'inconformidade' dos meninos, eles trataram o caso com mais rigor, o que certamente implicou na obtenção de um dado que recebeu tratamento diferenciado dos demais na sua tomada; procedimento que não poderia ter sido feito.

Neste módulo também foram realizadas duas demonstrações experimentais para complementar o estudo sobre o som, as quais não geraram resultados para este trabalho. Primeiro foi realizada uma experiência para análise da ressonância utilizando o aplicativo gerador de áudio e um aparato construído com material alternativo (uma lata, plástico fino e 
pó de rolha - Fig. 7). Posteriormente, também construído com material alternativo, um aparato experimental para a "demonstração da voz", sendo composto por um funil de papelão grosso (retrós de linha grande), apontador laser, balão, fita durex (Fig. 7). Com este equipamento os alunos puderam constatar características e diferenças da voz entre meninos e meninas. Nesta atividade os alunos interagiram verificando a "forma" da própria voz utilizando o aparato experimental (Fig. 8). Constataram que havia uma diferença na voz dos meninos e das meninas, devido à forma do feixe de luz produzido na tela. Uma menina concluiu para turma que isso era devido à voz dos meninos ter maior intensidade.

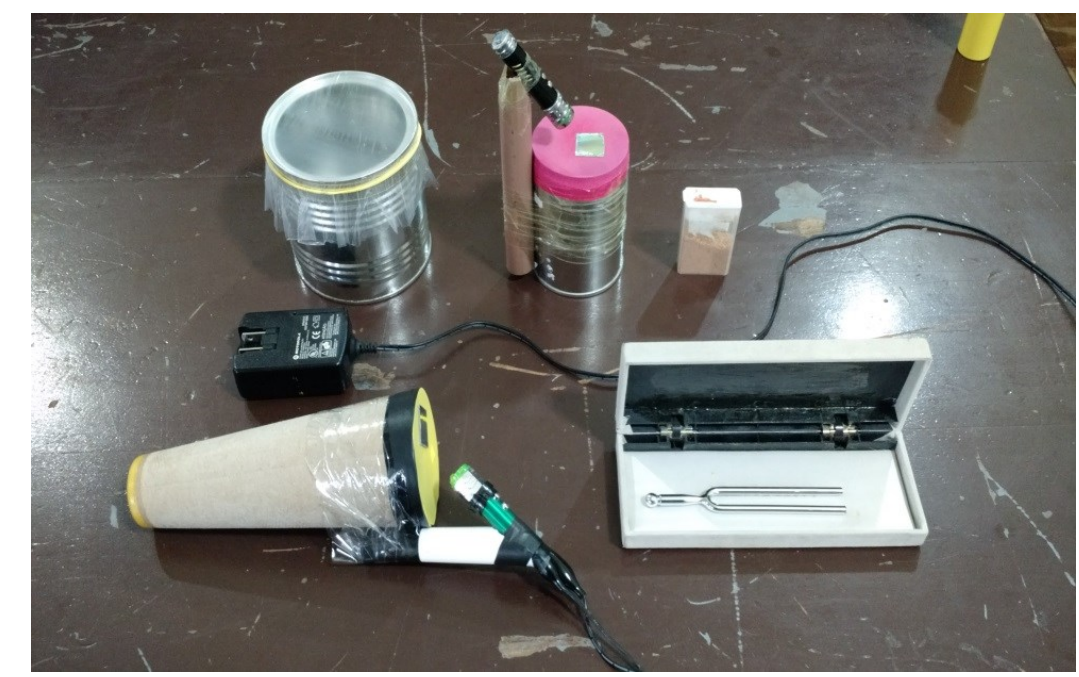

Fig. 7 - Aparatos experimentais construídos e diapasão: materiais utilizados para realizar as demonstrações experimentais.

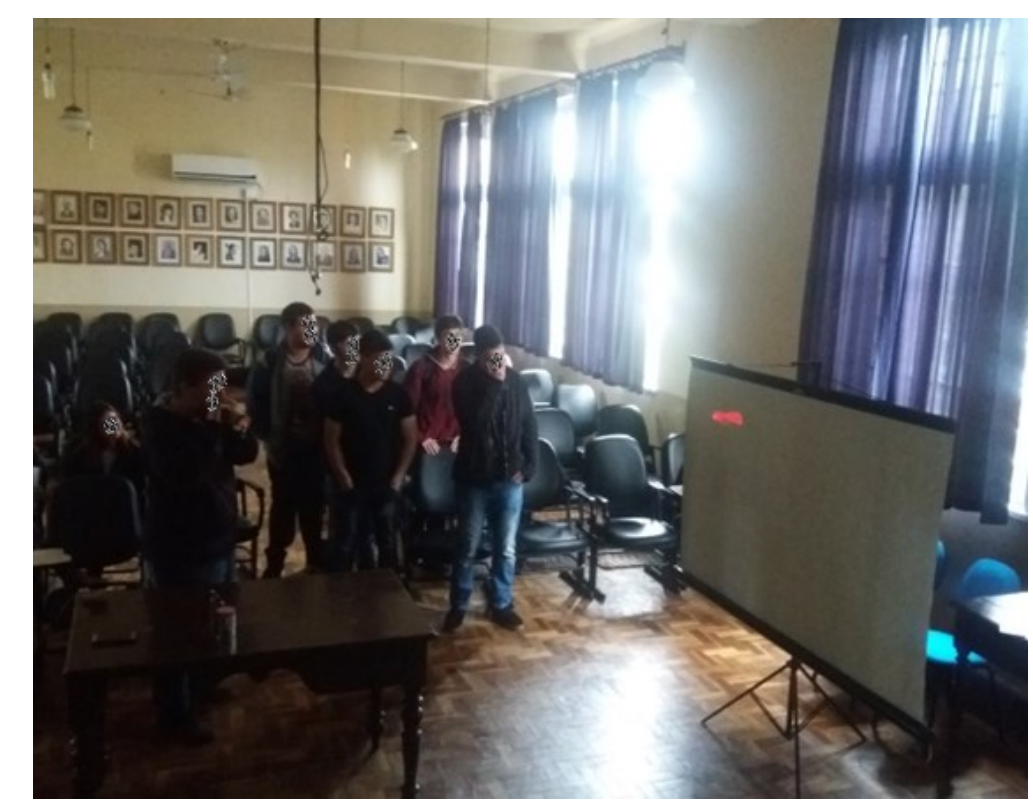

Fig. 8 - Módulo III da oficina: os alunos realizando a atividade onde podiam verificar a "forma" da sua voz com um feixe de luz projetado na tela. 
Nesta última atividade estavam presentes os doze alunos da turma, mas, apenas oito entregaram as respostas anotadas no material fornecido entregue a eles.

\section{Considerações finais}

Para o planejamento e desenvolvimento deste trabalho, foram analisados vários estudos sobre propostas de investigação, atividades experimentais e a utilização de aplicativos de smartphones em substituição a equipamentos caros, os quais dificilmente são encontrados em laboratórios escolares. Estes estudos foram, além de necessários, enriquecedores, contribuindo para tornar a ideia principal do trabalho possível de ser colocada em prática.

Ao acompanharmos todo o processo de aplicação das propostas, constatamos que os alunos já detinham alguns conhecimentos sobre o tema estudado e que suas atitudes, na execução das atividades, exteriorizam qualidades como iniciativa, determinação, envolvimento e organização.

Fazendo-se a análise desse processo, pode-se constatar aquilo que os diversos autores referidos destacam em seus estudos, como o engajamento e a tomada de decisão por parte dos alunos, tornando-os autônomos e construtores de conhecimentos; os quais analisam e interpretam dados e também fazem uma reflexão sobre os resultados encontrados. Essas constatações estão em consonância com o que apontam Wesendonk e Prado quando o tipo de experimento envolve atividades em que:

\section{[...] a ênfase é dada a um problema, que deve ser relevante para o aluno e por eles apropriado, consistindo, dessa forma, em uma pequena investigação dos alunos mediada pelo professor, com muito mais controle dos tempos e dos meios por parte dos alunos. [...] Os experimentos de caráter investigativo representam uma perspectiva que permitem aos alunos ocuparem uma posição mais ativa durante a montagem e realização da atividade, assim, tornando-se sujeitos no processo de construção do conhecimento. É possível a intervenção elou modificação de alguma etapa ou elemento da atividade pelos alunos (WESENDONK; PRADO, 2015, p. $62)$.}

Acredita-se que o resultado deste trabalho fornece indícios "de como se desenvolvem os processos de aprendizagem buscando melhorias na qualidade do ensino da disciplina de Física" (JUNIOR; COELHO, 2013, p. 8).

Percebeu-se, de forma consistente, que houve o "desenvolvimento da capacidade de reflexão, abstração, generalização, síntese e senso crítico" (ARAUJO; ABIB, 2003) esperado para esse tipo de proposta. Os alunos demonstraram um saber-fazer e um saber-proceder muito próximos ao que se esperaria de uma abordagem típica de investigações científicas, obtendo relações empíricas pertinentes às diversas situações e circunstâncias envolvidas. 


\section{Referências bibliográficas}

ARAÚJO, M.S.T.; ABIB, M. L. V. S. Atividades experimentais no ensino de física: diferentes enfoques, diferentes finalidades. Revista Brasileira de ensino de Física, v. 25, n. 2, p. 176-194, 2003. Disponível em: <http://www.scielo.br/pdf/rbef/v25n2/a07v25n2.pdf > Acesso em: 27 dez. 2017.

AZEVEDO, M. C. P. S. Ensino por Investigação: problematizando as atividades em sala de aula. Ensino de Ciências: Unindo a Pesquisa e a Prática. In: CARVALHO, A. M. P de (Org.). Ensino de Ciências: Unindo a Pesquisa e a Prática. São Paulo: THOMSON, 2006.

BARBOSA, C. D.; GOMES, L. M.; CHAGAS, M. L. das; FERREIRA, F. C. L. O uso de simuladores via smartphone no ensino de Física: O experimento de Oersted. Revista Scientia Plena, v. 13, n. 1, 2017. Disponível em:

$<$ https://scientiaplena.org.br/sp/article/view/3358/1644>. Acesso em: 19 jul. 2018.

BORGES, A. T. Novos Rumos para o Laboratório Escolar de Ciências. Caderno Brasileiro de Ensino de Física, v. 19, n. 13, p. 291-313, 2002. Disponível em:

$<$ https://periodicos.ufsc.br/index.php/fisica/article/view/6607/609> Acesso em: 20 out. 2018.

BRASIL. Secretaria da Educação. Parâmetros Curriculares Nacionais: Ciências Naturais. Brasília: MEC/SEF, 1999.

Delizoicov, D.; ANGotTi, J. A. Metodologia do Ensino de Ciências. São Paulo: Cortez, 1994.

FERNANDES, M. M.; SILVA, M. H. S. O trabalho experimental de investigação: das expectativas dos alunos às potencialidades no desenvolvimento de competências. Revista Brasileira de Pesquisa em Educação em Ciências, v. 4, n. 1, p. 45-58, 2004.

GUEDES, A. G. Estudo de ondas estacionárias em uma corda com a utilização de um aplicativo gratuito para smartphones. Revista Brasileira de Ensino de Física, v. 37, n. 2, 2015. Disponível em: <http://dx.doi.org/10.1590/S1806-11173721666> Acesso em: 01 out. 2018 .

JUNIOR, D. R. S.; COELHO, G. R. Ensino por investigação: problematizando as aprendizagens em uma atividade sobre condutividade elétrica. In: ENCONTRO NACIONAL DE PESQUISA EM EDUCAÇÃO EM CIÊNCIAS, 9, 2013. Águas de Lindóia. Anais... Disponível em: $<$ http://www.nutes.ufrj.br/abrapec/ixenpec/atas/resumos/R0600-1.pdf $>$. Acesso em: 01 out. 2018. 
PARENTE, A. G. L. Práticas de investigação no ensino de ciências: percursos de formação de professores. 2012. 234p. Tese (Doutorado) - Faculdade de Ciências, Universidade Estadual Paulista, Bauru.

PhET INTERACTIVE SIMULATIONS. University of Colorado Boulder. Disponível em: $<$ https://phet.colorado.edu/pt_BR/simulation/legacy/sound>. Acesso em: 15 set. 2018.

SILVA, L. R. C. O uso de aplicativos para smartphones e tablets no ensino de física: análise da aplicabilidade em uma universidade pública no Estado do Rio Grande do Sul. In: CONGRESSO NACIONAL DE EDUCAÇÃO, XI, EDUCERE. Disponível em:

$<$ http://educere.bruc.com.br/arquivo/pdf2017/23096_11831.pdf>. Acesso em: 24 out. 2018.

STEFAnOVITS, A. Ser Protagonista: Física, $2^{\circ}$ ano: Ensino Médio. 2. ed. São Paulo: Edições SM, 2013. v. 2.

STEFFANI, M. H. et al. "Vendo o som" com o uso das Novas Tecnologias de Informática e Comunicação. ResearchGate, 2014. Disponível em:

$<$ https://www.researchgate.net/publication/228817189_Vendo_o_som_com_o_uso_das_Nova s_Tecnologias_de_Informatica_e_Comunicacao>. Acesso em: 15 jun. 2018.

WESENDONK, F. S.; PRADO, L. Atividade didática baseada em experimento: discutindo a implementação de uma proposta investigativa para o Ensino de Física. Revista Experiências em Ensino de Ciências, v. 10, n. 1, abr. 2015. Disponível em:

$<$ http://if.ufmt.br/eenci/artigos/Artigo_ID265/v10_n1_a2015.pdf>. Acesso em: 27 dez. 2017.

\section{Anexo}

\section{Aplicativos utilizados na oficina}

1) Decibelímetro: Sound Meter versão 1.6.15 da empresa Smart Tools co. 


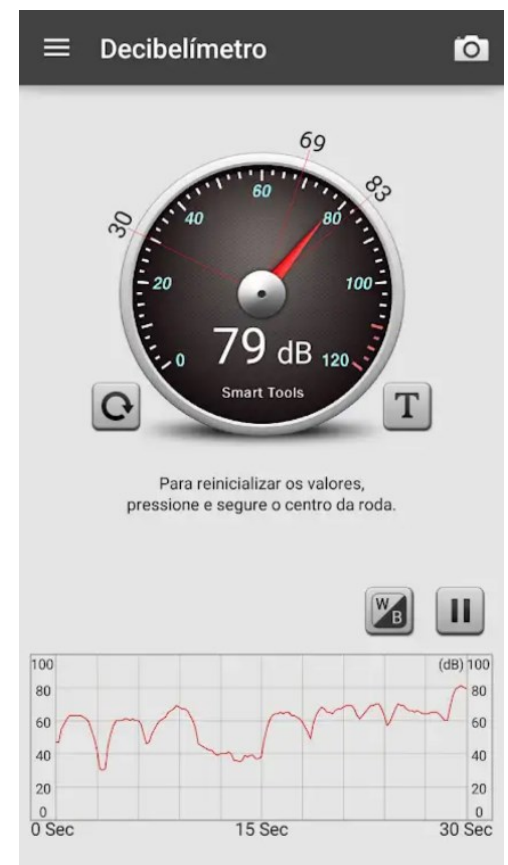

Fig. 9 - Aplicativo decibelímetro Sound Meter.

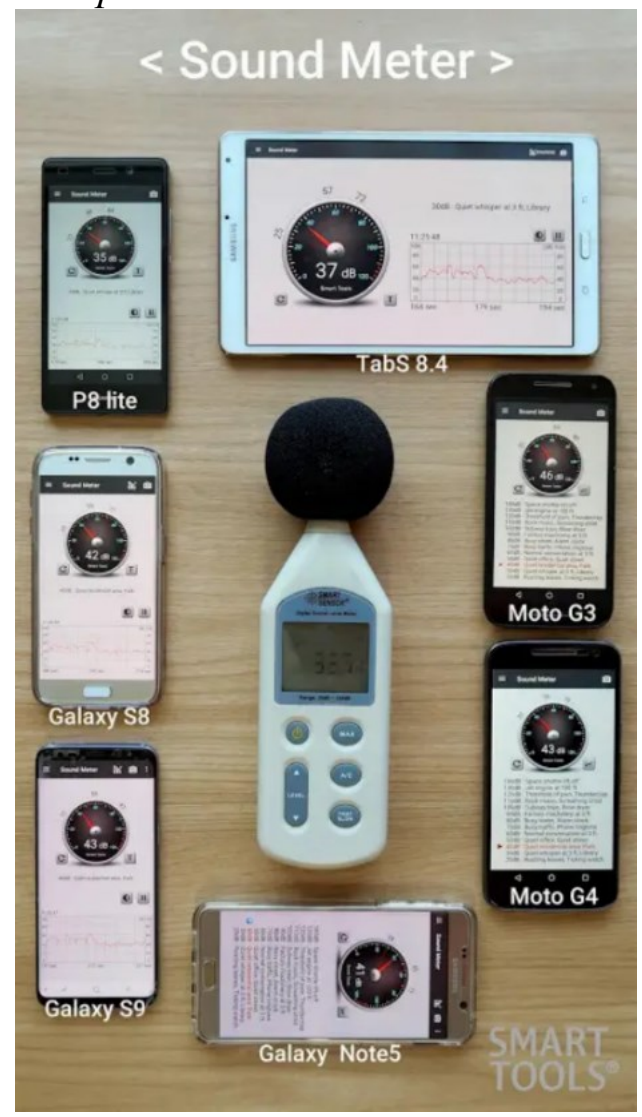

Fig. 10 - Calibração do aplicativo decibelímetro Sound Meter com um aparelho medidor de decibéis em diferentes smartphones. 


\section{Informações do Fabricante (adaptação e correções nossas):}

O aplicativo SPL (nível de pressão sonora) usa o microfone embutido no seu dispositivo para medir o volume de ruído em decibéis $(\mathrm{dB})$, e mostra uma referência. A maioria dos microfones está calibrado para a voz humana (300-3.400 Hz, 40-60 dB). Chamadas de voz não exigem microfones de alto desempenho. Portanto, os valores máximos são limitados pelos fabricantes e o som muito forte (acima de $100 \mathrm{~dB}$ ) não pode ser reconhecido. Exemplo: Moto G4, máximo de 94 dB; Galaxy S6, máximo de 85 dB; Nexus 5, máximo de $82 \mathrm{~dB}$; HTC Desire, máximo de $82 \mathrm{~dB}$ (Fig. 7). O desenvolvedor calibrou os principais dispositivos com o sistema operacional Android utilizando um medidor de som real (dBA) e verificou a confiabilidade dos resultados em níveis de ruído comuns (40-70 dB), recomendando o uso do aplicativo como ferramenta auxiliar.

2) Gerador de áudio: Frequency Sound Generator versão 2.10 da empresa BialaMusic. Oferecido por Fine Chromatic Tuner. Desenvolvedor: Aleksandar Mlazev.

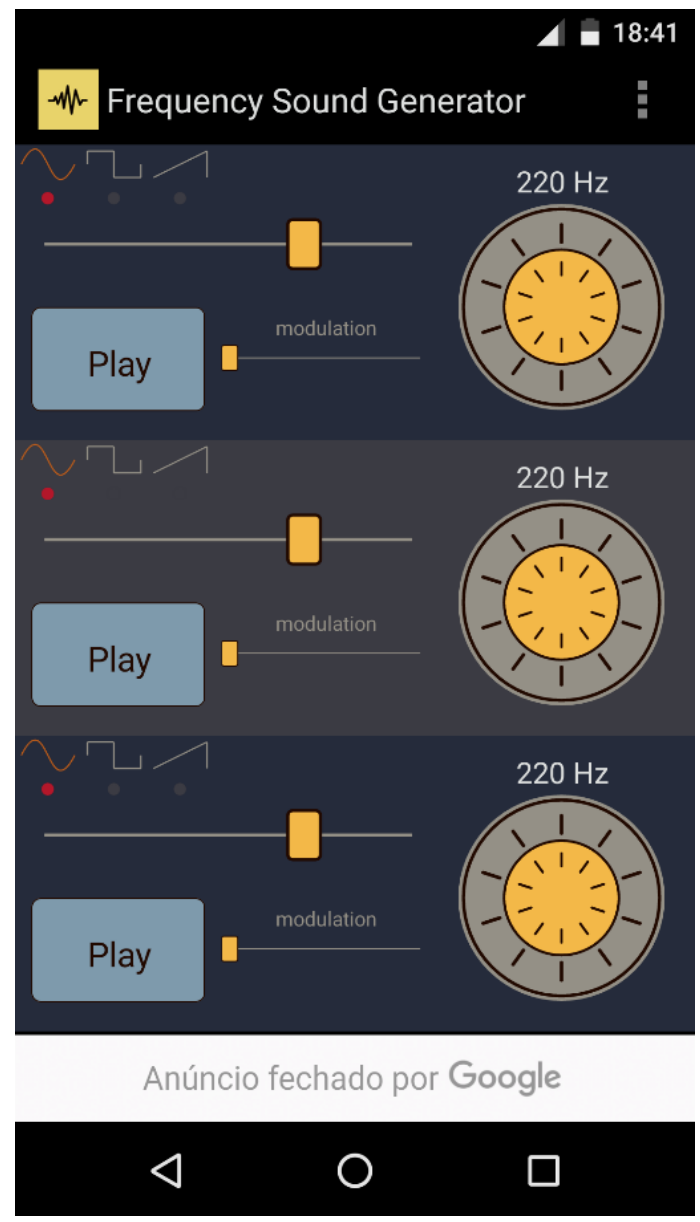

Fig. 11 - Aplicativo gerador de áudio Frequency Sound Generator. 


\section{Informações do Fabricante (tradução e adaptação nossas):}

Frequency Sound Generator é um simples gerador de ondas sonoras e oscilador. E fácil usar esta ferramenta para criar uma grande variedade de sons e sinais em apenas alguns segundos. Todos os controles estão em tempo real para poder alterar dinamicamente os sinais sonoros.

Características: Faixa de oscilação de $0,1 \mathrm{~Hz}$ até $20 \mathrm{kHz}$; três osciladores que podem gerar três formas de onda cada um; seletor preciso de frequência com controle lento e rápido; controle de volume; controle de modulação do sinal; dois seletores de velocidade de frequência; salva e carrega sons.

3) Frequencímetro: Audio Frequency Counter versão 1.03 da empresa Keuwlsoft.

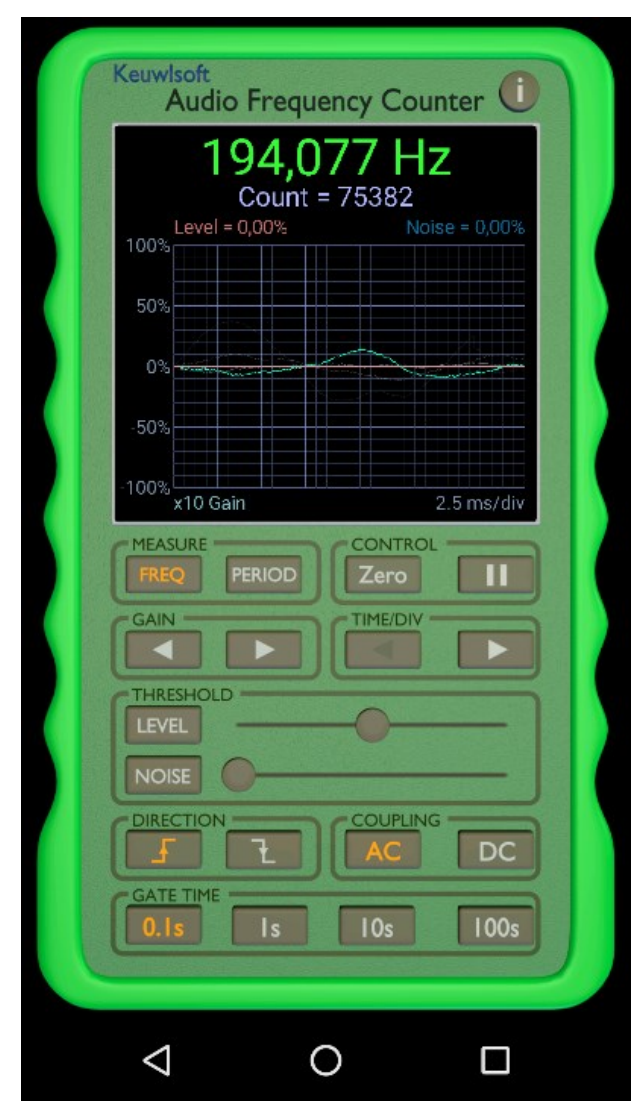

Fig. 12 - Aplicativo frequencímetro Audio Frequency Counter.

\section{Informações do fabricante (tradução e adaptação nossa):}

Contador de frequência baseado na captação do microfone. As contagens acontecem quando o nível de a entrada sobe ou desce de um determinado nível, convertendo em frequência ou em um período de tempo. Os resultados dependem do dispositivo e do hardware utilizados. Este aplicativo pode fornecer medição de frequência mais precisa para 
sinais de entrada de frequência simples. Não deve ser usado como padrão de referência. Defina um nível de ruído para que o novo evento não seja acionado até que o sinal tenha primeiro passado desse nível.

Características: Mostrador que exibe a contagem de eventos disparados e a frequência ou o período de tempo; gráfico do sinal de entrada com faixa de $2.5 \mathrm{~ms} / \mathrm{div}$. até $640 \mathrm{~ms} /$ div.; passagem de tempo com faixas de $0,1 \mathrm{~s}, 1 \mathrm{~s}, 10 \mathrm{~s}$ ou $100 \mathrm{~s}$; incremento de $1 \mathrm{vez}$ até 1.000 vezes; gatilho em subida ou descida; acoplamento AC ou DC.

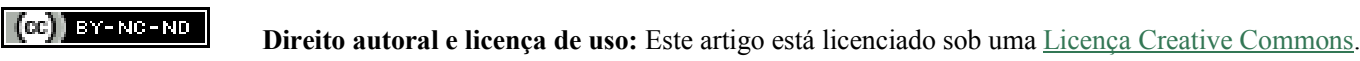

